\title{
Comparative Analysis between Transferred and Self-Referred STEMI Patients Undergoing Primary Angioplasty
}

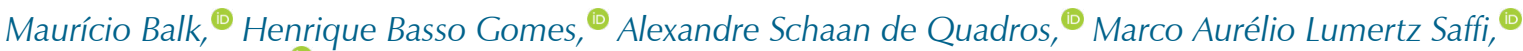 \\ Tiago Luiz Luz Leiria \\ Instituto de Cardiologia - Fundação Universitária de Cardiologia (IC/FUC), Porto Alegre, RS - Brazil
}

\section{Abstract}

Background: Studies have shown the benefits of rapid reperfusion therapy in acute myocardial infarction. However, there are still delays during transport of patients to primary angioplasty.

Objective: To evaluate whether there is a difference in total ischemic time between patients transferred from other hospitals compared to self-referred patients in our institution.

Methods: Historical cohort study including patients with acute myocardial infarction treated between April 2014 and September 2015. Patients were divided into transferred patients (group A) and self-referred patients (group B). Clinical characteristics of the patients were obtained from our electronic database and the transfer time was estimated based on the time the e-mail requesting patient's transference was received by the emergency department.

Results: The sample included 621 patients, 215 in group A and 406 in group B. Population characteristics were similar in both groups. Time from symptom onset to arrival at the emergency department was significantly longer in group A (385 minutes vs. 307 minutes for group B, p $<0.001)$ with a transfer delay of 147 minutes. There was a significant relationship between the travel distance and increased transport time $(R=0.55, p<0.001)$. However, no difference in mortality was found between the groups.

Conclusion: In patients transferred from other cities for treatment of infarction, transfer time was longer than that recommended, especially in longer travel distances. (Arq Bras Cardiol. 2019; 112(4):402-407)

Keywords: ST Elevation Myocardial Infarction/complications; Angioplasty, Balloon, Coronary/methods; Myocardial Reperfusion/methods; Fibrinolytic Agents; Intensive Care Units.

\section{Introduction}

For patients presented within 12 hours of ST-segment elevation acute myocardial infarction (STEMI), reperfusion therapy with thrombolytic agent or percutaneous transluminal coronary angioplasty (PTCA) should be provided as early as possible. ${ }^{1} \mathrm{~A}$ shorter time-to-treatment in infarcted patients is associated with greater myocardial salvage and has a positive effect on ventricular function and mortality. ${ }^{2,3}$

PTCA is the therapy of choice for coronary reperfusion, if initiated within 90 minutes from AMI diagnosis or 120 minutes for patients referred for PTCA at another center. ${ }^{4,5}$ Nevertheless, some factors contribute to increasing time-to-treatment: a) unawareness of AMI-related signs and symptoms by the patients; b) unawareness of the benefits of a rapid reperfusion therapy; c) lack of healthcare facilities adequately equipped to early detect patients with STEMI; d) delay in defining the most appropriate reperfusion therapy and patient transportation delay. ${ }^{6}$

Mailing Address: Tiago Luiz Luz Leiria •

Av. Princesa Isabel, 370. Postal Code 90620-000, Santana, Porto Alegre RS - Brazil

E-mail: pesquisa.leiria@gmail.com, editoracao-pc@cardiologia.org.br Manuscript received May 18, 2018, revised manuscript July 29, 2018, accepted August 02, 2018

DOI: $10.5935 / a b c .20190014$
For example, in hospitals for less complex cases, PTCA is not available, and the use of thrombolytic therapy or the transfer of patients to more specialized hospitals cause a delay in $\mathrm{AMI}$ treatment.

In many countries, an integrated care system for STEMI is already available. ${ }^{7}$ Strategies aimed at reducing the time to STEMI diagnosis and treatment are needed. However, data on inter-hospital transfer of patients in Brazil are scarce. The present study aimed at determining whether there are differences in total ischemic time between patients referred from other hospitals and those who self-referred, based on current guidelines' recommendations. ${ }^{8-10}$

\section{Methods}

Study design

This was a historical cohort study.

\section{Characteristics of inter-hospital transfer of patients}

The normal procedure for accepting a patient's transfer for treatment of STEMI involves the receipt of an electrocardiography report (ECG) confirming the diagnosis of STEMI (previously by fax, and recently by e-mail). This would avoid costs in the health system with incorrect diagnosis and unnecessary referral to the emergency department. 


\section{Subjects}

Patients with diagnosis of STEMI registered in the database of the Institute of Cardiology of the University Foundation of Cardiology (IC-FUC) were assessed and allocated to one of two groups - Group A, patients whose names and electrocardiographic results were listed in the electronic mailbox of the emergency department, confirming the approximate time of contact and indicating the place of origin - and Group B, self-referred patients (all others).

Transfer time ( $\mathrm{min}$ ) was calculated by subtracting the time and the day the message (containing ECG result attached) was received from the time and day patients were admitted to the emergency department (according to medical records).

\section{Ethical consideration}

The study was registered at the research unit of the IC-FUC and approved by the local ethics committee.

\section{Statistical analysis}

Continuous variables were expressed as mean \pm standard deviation or median and interquartile range, as appropriate. Categorical variables were presented as absolute number and percentage and compared by the chi-square test and Z-test. Continuous variables were analyzed using Student's t-test for independent samples or the Wilcoxon-Mann-Whitney test, as appropriate. Normality was tested by the D'Agostino-Pearson test. Our database was constructed using Microsoft Excel 2010 software and then transferred to the IBM Statistical Package for the Social Sciences (SPSS) version 19.0.0. The SPSS software version 18.0 was used for statistical analysis. Two-tailed p-values $<0.05$ were considered statistically significant.

\section{Results}

E-mail messages received by the emergency department of the IC-FUC between April 2014 and September 2015 were reviewed. ECG results showing ST-segment elevation and identification data of patients were cross-checked with data registered in the $\mathrm{AMI}$ database of the hospital.

During the study period, 2,532 pieces of information were excluded - 68 messages in which patients' names could not be identified, 869 ECG results of patients with non-STEMI, 381 duplicate messages, 23 "unknown hard error" messages, 491 tomography reports, 408 internal messages, and 292 ECG results of patients with STEMI that had not been referred from other hospitals or patients not registered in the AMI database.

Final sample was composed of 621 patients, 215 transferred patients (group A) and 406 self-referred (group B).

Table 1 describes characteristics of groups A and B. Both groups had similar risk factors.

Figure 1 depicts mean variation in the time elapsed from symptom onset to arrival at emergency department (delta T) and the travel distance of patients, depending on the place of origin.

Mean delta T of all patients was 334 minutes. Mean delta $\mathrm{T}$ of patients transferred by emergency medical services of the Secretariat of Health (group A) was 385 minutes, with a delay in transfer time of 147 minutes. Mean delta T of group B was 307 minutes (Figure 2).

Figure 3 shows a scatter plot of delta T and travel distance, with a good correlation coefficient between these variables $(R=0.55$ and $p<0.001)$. Despite that, the graphs shows a number of cities with shorter travel distances but higher transfer times (plots above diagonal), and cities with longer travel distances but shorter transfer time (plots below diagonal).

Despite the statistical difference in transfer time, no difference in mortality was observed between the groups.

\section{Discussion}

Treatment of STEMI is considered a medical emergency, with significant mortality even in well renowned centers. ${ }^{11}$ The main objective of the therapy is restoration of blood flow in the culprit vessel. This is achieved by administration of fibrinolytic agents to dissolve intracoronary thrombus, or by PTCA, with percutaneous recanalization of the infarct artery with or without stent implantation. In the present study, we demonstrated the difference in delta T between STEMI patients referred for PTCA and self-referred STEMI patients to the emergency department of the IC-FUC

The finding that transferred patients have longer ischemia time and a longer time to coronary reperfusion therapy is not a surprise, since in these cases there are delays in contacting

Table 1 - Characteristics of patients referred from other hospitals (group A) and self-referred patients (group B). Porto Alegre, RS, Brazil

\begin{tabular}{|c|c|c|c|}
\hline Variable & Group A ( $n=215)$ & Group $B(n=406)$ & $\mathrm{p}$ \\
\hline Age, years ${ }^{*}$ & $58(28-87)$ & $60(18-98)$ & 0.50 \\
\hline Male sex $†$ & $145(67)$ & $283(69)$ & 0.67 \\
\hline \multicolumn{4}{|l|}{ Risk factors† } \\
\hline Hypertension & $128(59)$ & 251 (61) & 0.69 \\
\hline Smoking & $148(68)$ & 249 (61) & 0.10 \\
\hline Dyslipidemia & $67(31)$ & $132(32)$ & 0.86 \\
\hline Diabetes & $55(25)$ & $96(23)$ & 0.64 \\
\hline Family history & $45(20)$ & $109(26)$ & 0.11 \\
\hline
\end{tabular}

${ }^{*}$ Data presented as median and interquartile range; $†$ Absolute and relative frequency. 


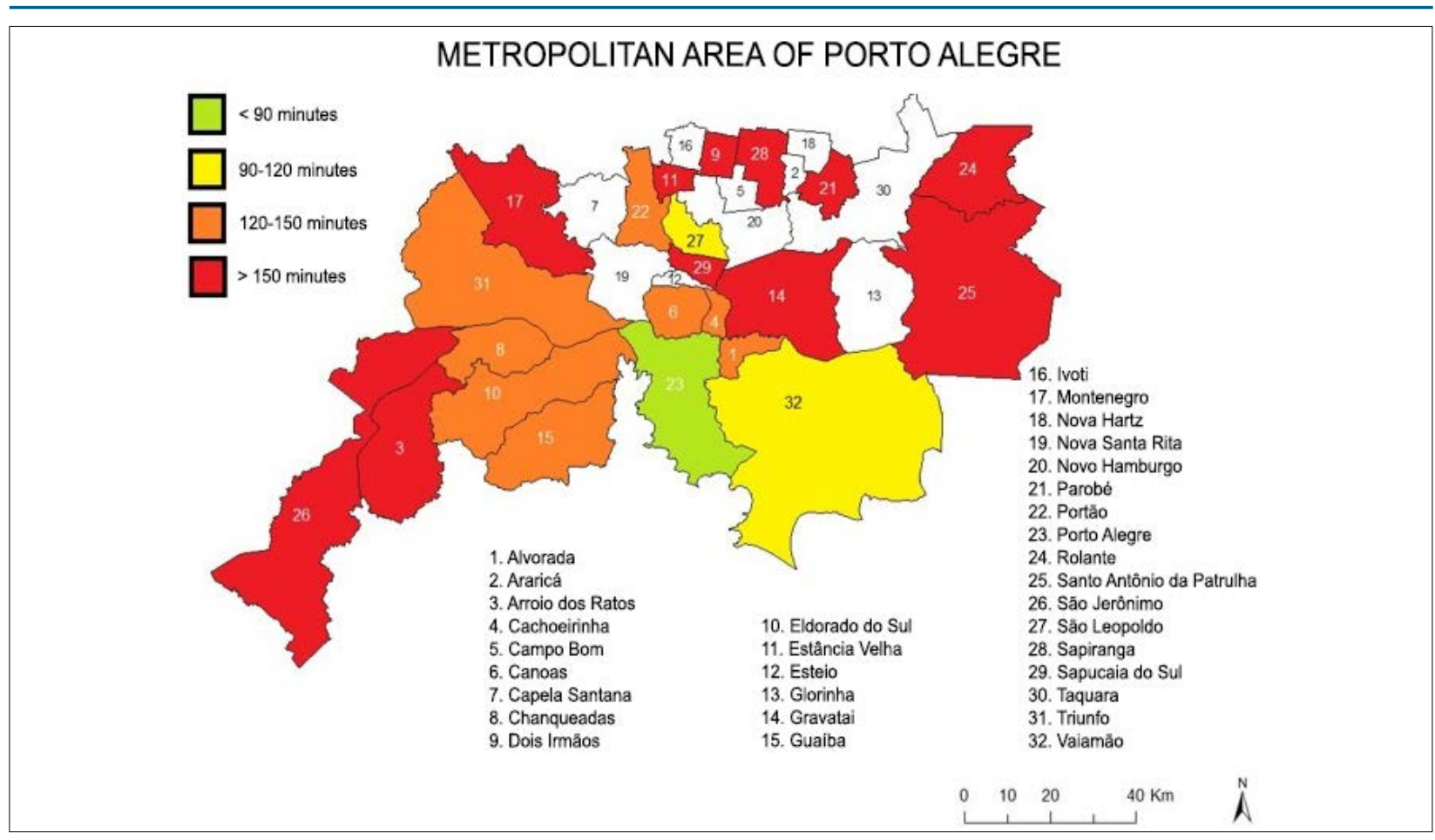

Figure 1 - Map of the metropolitan area of Porto Alegre, illustrating the regions by names and mean patient transport time to the Institute of Cardiology, University Foundation of Cardiology (IC-FUC).

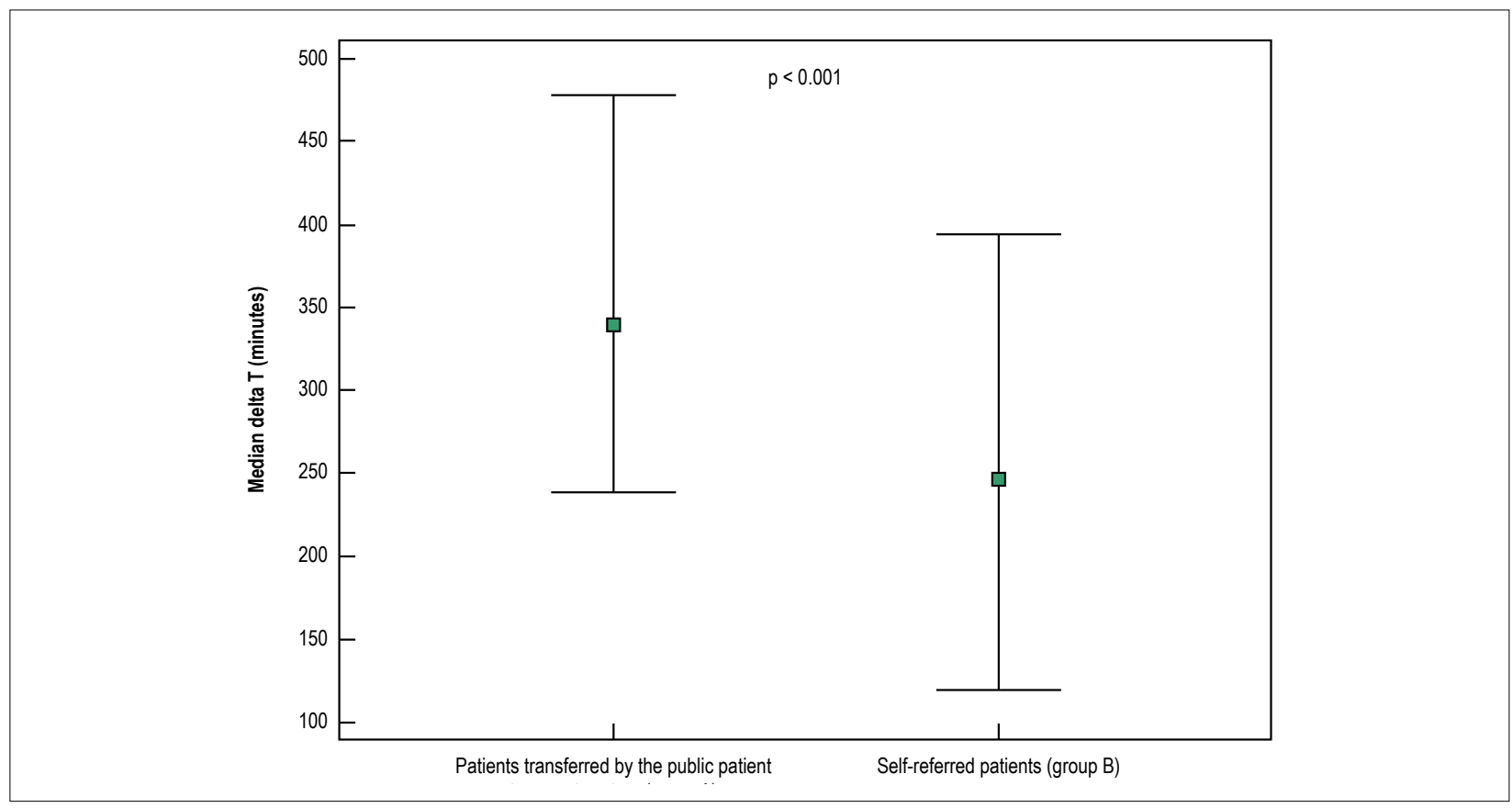

Figure 2 - Comparison of median delta T between patients transferred from other institutions and self-referred patients.

medical and transport services, in obtaining authorization from the emergency medical services for ambulance services and in patients' transportation itself.

According to the Brazilian guidelines, PTCA is the preferred option for coronary reperfusion, if initiated within
90 minutes from diagnosis of STEMI or within 120 minutes in case of patients referred for therapy at other centers. ${ }^{8}$ It is worth pointing out that, in patients treated with PTCA, for each 30 minutes of delay, relative risk for mortality increases $7.5 \% .^{12}$ 


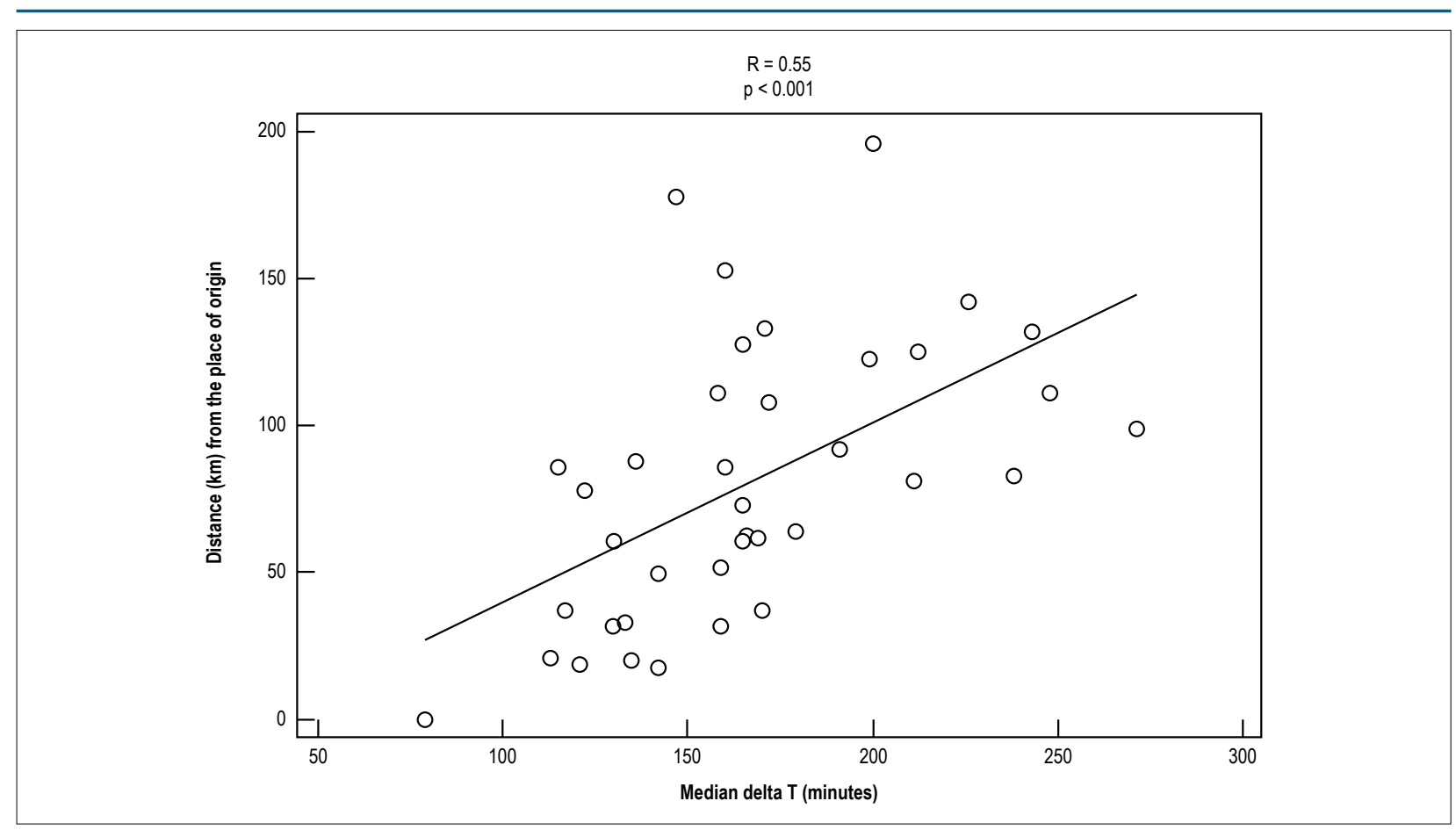

Figure 3 - Correlation between distance from the place of origin and mean delta $T$ (minutes).

In a time period lower than 2 hours, primary PTCA was superior to fibrinolytic therapy in terms of severe adverse effects (death, stroke and reinfarction; ${ }^{13}$ event rates were $8.5 \%$ vs $14.2 \%$, respectively; $p=0.02$ ).

The benefit of transferring STEMI patients for PTCA on in-hospital mortality, compared with onsite fibrinolytic therapy, decreased as transfer time increased. In-hospital mortality was $2.7 \%, 3.6 \%$ and $5.7 \%$ in PTCA group and $7.4 \%, 5.5 \%$ and $6.1 \%$ in fibrinolytic therapy group for delays of 0-60 minutes, 60-90 minutes and longer than 90 minutes, respectively. ${ }^{14}$

In our study, mean transfer time was 141 minutes, with wide variation according to patients' place of origin. In the cities of Porto Alegre, Viamão and São Leopoldo, transfer time was shorter than 120 minutes. In all other cities, however, it was longer than recommended, reducing the benefits of the immediate transport of patients for primary angioplasty.

Figure 1 more clearly illustrates the relationship between travel distance and prolonged transfer time. White areas in the map correspond to cities where no transfer of STEMI patients for primary angioplasty was registered. Therefore, patients from these areas were not included for analysis, although it is likely that their transfer times were similar to those in the cities nearby, and higher than predicted.

An arm of the GRACE study with 3,959 patients compared fibrinolytic therapy with primary angioplasty, and showed a door-to-needle time of 35 minutes and door-to-balloon time of 78 minutes. Treatment delays were associated with an increase in 6-month mortality for both therapies. For each 10 -min delay in door-to-needle, mortality increased by $0.30 \%$ for patients who underwent thrombolysis, and $0.18 \%$ for those who underwent primary $\mathrm{PCl} .{ }^{15}$

In patients with chest pain treated within 3 hours of symptom onset, no difference in mortality was observed between PTCA and fibrinolysis (7.2\% vs. 7.4\%). Nevertheless, in those treated between 3-12 h after symptom onset, mortality significantly increased in fibrinolysis group compared with PTCA (6.0\% vs. $15.3 \%){ }^{16}$

In centers without catheterization facilities, i.e., when patient transfer is required, thrombolysis should be performed, since, if carried out within 3 hours of STEMI, both angioplasty and thrombolytic therapy have similar benefit on mortality. Besides, between 3 hours and 12 hours of pain onset, in places where transfer time is expected to be longer than ideal transfer time, thrombolysis should be strongly considered.

For calculation of the total ischemic time, one should consider the delay in seeking medical care, the time until AMI diagnosis, delays in patients' transfer to the catheterization laboratory, and internal delays of the referral system, from patients' enrollment to the opening of the infarct-related artery. In a previous study performed in our institution, the mean time from symptom onset to hospital admission was 90 minutes during business hours and 133 minutes outside this period. ${ }^{17}$

\section{Limitations of the study}

Despite the quantitative nature of delta $\mathrm{T}$, this variable can be difficult to be evaluated, resulting in measurement errors. In addition, since this study consisted in a database review, there are potential biases, inherent to this type of analysis. 


\section{Conclusion}

The present study shows that AMI patients transferred from other institutions have prolonged ischemic time, exceeding that recommended by the Brazilians guidelines. However, ischemic time varied largely between the cities, in a direct proportion to the distance covered. These findings can help health managers in identifying how to improve patient transport system, leading to earlier reperfusion therapy and mortality reduction.

\section{Author contributions}

Conception and design of the research: Balk $M$. Acquisition of data: Balk M, Gomes HB. Statistical analysis: Saffi MAL, Leiria TLL. Writing of the manuscript: Saffi MAL, Leiria TLL. Critical revision of the manuscript for intellectual content: Gomes HB, Quadros AS, Leiria TLL.

\section{Potential Conflict of Interest}

No potential conflict of interest relevant to this article was reported.

\section{References}

1. Keeley EC, Boura JA, Grines CL. Primary angioplasty versus intravenous thrombolytic therapy for acute myocardial infarction: a quantitative review of 23 randomised trials. Lancet. 2003;361(9351):13-20.

2. Pinto DS, Kirtane AJ, Nallamothu BK, Murphy SA, Cohen DJ, Laham RJ, et al. Hospital delays in reperfusion for ST-elevation myocardial infarction: implications when selecting a reperfusion strategy. Circulation. 2006;114(19):2019-25

3. Gibson CM. Time is myocardium and time is outcomes. Circulation. $2001 ; 104(22): 2632-4$

4. Nielsen PH, Terkelsen CJ, Nielsen TT, Thuesen L, Krusell LR, Thayssen P, et al. System delay and timing of intervention in acute myocardial infarction (from the Danish Acute Myocardial Infarction-2 [DANAMI-2] trial). Am J Cardiol. 2011;108(6):776-81.

5. Sorensen JT, Terkelsen CJ, Norgaard BL, Trautner S, Hansen TM, Botker HE, et al. Urban and rural implementation of pre-hospital diagnosis and direct referral for primary percutaneous coronary intervention in patients with acute ST-elevation myocardial infarction. Eur Heart J. 2011;32(4):430-6.

6. Finnegan JR, Meischke H, Zapka JG, Leviton L, MeshackA, Benjamin-Garner $\mathrm{R}$, et al. Patient delay in seeking care for heart attack symptoms: findings from focus groups conducted in five U.S. regions. Prev Med. 2000;31(3):205-13.

7. Henry TD, Sharkey SW, Burke MN, Chavez IJ, Graham KJ, Henry CR, et al. A regional system to provide timely access to percutaneous coronary intervention for ST-elevation myocardial infarction. Circulation. 2007;116(7):721-8.

8. Piegas LS, Timerman A, Feitosa GS, Nicolau JC, Mattos LAP, Andrade MD, et al., Sociedade Brasileira de Cardiologia. V Diretriz da Sociedade Brasileira de Cardiologia sobre tratamento do infarto agudo do miocárdio com supradesnível do segmento ST. Arq Bras Cardiol. 2015;105(2):1-105.

9. Ibanez B, James S, Agewall S, Antunes MJ, Bucciarelli-Ducci C, Bueno H, et al. 2017 ESC Guidelines for the management of acute myocardial infarction in patients presenting with ST-segmentelevation: The Task Force for the management of acute myocardial infarction in patients presenting with ST-segmentelevation of the European Society of Cardiology (ESC). Eur HeartJ. 2018;39(2):119-77.

\section{Sources of Funding}

There were no external funding sources for this study.

\section{Study Association}

This study is not associated with any thesis or dissertation work.

\section{Ethics approval and consent to participate}

This study was approved by the Ethics Committee of the Instituto de Cardiologia - Fundação Universitária de Cardiologia (IC/FUC), under the protocol number 5565/18. All the procedures in this study were in accordance with the 1975 Helsinki Declaration, updated in 2013. Informed consent was obtained from all participants included in the study.
10. Levine GN, Bates ER, Blankenship JC, Bailey SR, Bittl JA, Cercek B, et al. 2015 ACC/AHA/SCAI Focused Update on Primary Percutaneous Coronary Intervention for Patients With ST-Elevation Myocardial Infarction: An Update of the 2011 ACCF/AHA/SCAI Guideline for Percutaneous Coronary Intervention and the 2013 ACCF/AHA Guideline for the Management of STElevation Myocardial Infarction. J Am Coll Cardiol. 2016;67(10):1235-50

11. Mann D, Zipes D, Libby P, Bonow R. Braunwald's heart disease:a textbook of cardiovascular medicine. 10th Philadelphia: Saunders/Elsevier; 2014. p.1133-99.

12. De Luca G, Suryapranata H, Ottervanger JP, Antman EM. Time delay to treatment and mortality in primary angioplasty for acute myocardial infarction: every minute of delay counts. Circulation. 2004;109(10):1223-5.

13. Andersen HR, Nielsen TT, Rasmussen $K$, Thuesen $L$, Kelbaek $H$, Thayssen $P$ et al. A comparison of coronary angioplasty with fibrinolytic therapy in acute myocardial infarction. N Engl J Med. 2003;349(8):733-42.

14. Pinto DS, Frederick PD, Chakrabarti AK, Kirtane AJ, Ullman E, Dejam A et al. Benefit of transferring ST-segment-elevation myocardial infarction patients for percutaneous coronary intervention compared with administration of onsite fibrinolytic declines as delays increase. Circulation. $2011 ; 124(23): 2512-21$

15. Nallamothu B, Fox KA, Kennelly BM, Van de Werf F, Gore JM, Steg PG, et al. Relationship of treatment delays and mortality in patients undergoing fibrinolysis and primary percutaneous coronary intervention. The Global Registry of Acute Coronary Events. Heart. 2007;93(12):1552-5.

16. Widimsky P, Budesinsky T, Vorac D, Groch L, Zelizko M, Aschermann $M$, et al. Long distance transport for primary angioplasty vs immediate thrombolysis in acute myocardial infarction. Final results of the randomized national multicentre trial--PRAGUE-2. Eur Heart J. 2003;24(1):94-104.

17. Cardoso CO, Quadros AS, Voltolini I, Azmus AD, Cardoso CR, Sebben J, et al. Angioplastia primária no infarto agudo do miocárdio: existe diferença de resultados entre as angioplastias realizadas dentro e fora do horário de rotina? Rev Bras Cardiol Invasiva. 2010;18(3):273-80. 
Transfer time in STEMI patients

Original Article 